\title{
Effect of Reprocessing Cycles on the Morphology and Mechanical Properties of a Poly(Propylene)/Poly(Hydroxybutyrate) Blend and its Nanocomposite
}

\author{
Rosimery Rodrigues de Oliveira ${ }^{a}$, Thainá Araújo de Oliveira ${ }^{b}$ (D), \\ Lucas Rafael Carneiro da Silva ${ }^{b}$ (D), Renata Barbosa ${ }^{b}$ (D), Tatianny Soares Alves ${ }^{b *}$ (D), \\ Laura Hecker de Carvalho ${ }^{c}$, Daniele Tôrres Rodrigues ${ }^{d}$ \\ anstituto Federal do Piauí, Programa de Pós-Graduação em Engenharia de Materiais, 64.000-040, \\ Teresina, PI, Brasil \\ ${ }^{b}$ Universidade Federal do Piauí, Centro de Tecnologia, Programa de Pós-Graduação em Ciência e \\ Engenharia de Materiais, 64.049-550, Teresina, PI, Brasil \\ ${ }^{c}$ Universidade Federal de Campina Grande, Centro de Ciência e Tecnologia, Programa de Pós- \\ Graduação em Ciência e Engenharia de Materiais, 58.100-000, Campina Grande, PB, Brasil \\ ${ }^{d}$ Universidade Federal do Piaui, Departamento de Estatística, 64.049-550, Teresina, PI, Brasil
}

Received: August 16, 2020; Revised: March 22, 2021; Accepted: April 06, 2021

\begin{abstract}
The use of polymer blends and composites based on fossil-based and bio-based polymers has become an important environmentally protective alternative for common use and disposable plastics applications such as packaging, bottles and trays. The disposal of these more degradable products, however, may also harm the environment and, therefore, recycling these systems becomes relevant. Recycling involves reprocessing which can significantly change the morphology and properties of polymeric products. Therefore, this study deals with the effects of reprocessing cycles on the properties and morphology of blends and nanocomposites based on fossil and bio-based polymers. The systems investigated were: a) neat polypropylene (PP), b) a polypropylene/poly(3-hydroxybutyrate) (PP/PHB) blend and c) $\mathrm{PP} / \mathrm{PHB} /$ organoclay nanocomposite compatibilized with polypropylene-g-maleic anhydride (PP-g-MA) and erucamide. These materials were submitted to up to seven extrusion cycles in a single screw extruder operating at $60 \mathrm{rpm}$. Samples were taken after the first, third, fifth and seventh extrusion cycles and their tensile properties and morphology were determined. Scanning electron microscopy indicated that two phases were observed in the blend which showed spherical PHB domains. The addition of clay, PP-g-MA and erucamide improved the adhesion between the nanocomposites components. $\mathrm{X}$-ray diffraction analysis showed that crystallinity tended to increase with the number of reprocessing cycles for all systems investigated up to the fifth cycle and then tended to decrease. A $10 \%$ crystallinity increase was observed for neat PP in the fifth cycle. In general, the tensile properties of all systems decreased with reprocessing and the highest losses were observed for the PP/PHB blend after seven processing cycles with $50 \%$ and $37 \%$ decreases in stress at break and elastic modulus, respectively. Impact strength of the PP matrix and of the PP/PHB blend tended to decrease with reprocessing, except for the nanocomposite which showed a slight increase especially after the seventh processing cycle in which an $18 \%$ increase in impact strength was observed.
\end{abstract}

Keywords: reprocessing, cycles, morphology, mechanical, properties.

\section{Introduction}

Polymer consumption increases annually due to properties such as low density, easy processing and a wide range of applications. However, considering that the majority of petroleum-derived polymers degrade very slowly and most of these products improperly disposed, environmental problems arise with their use and disposal. Different policies have been adopted for the management of plastic waste, such as the reuse and recycling of these materials. Mechanical recycling is the most widely used alternative, mainly because it generates jobs and income and the reintroduction of the

*e-mail: tsaeng3@yahoo.com.br raw material reduces the use of virgin polymer, energy consumption, extraction of fossil inputs and carbon dioxide $\left(\mathrm{CO}_{2}\right)$ emissions ${ }^{1-4}$. Trends on current production and waste management indicate that by the year 2050, approximately 12,000 tonnes of non-biodegradable polymer waste will be disposed of in landfills ${ }^{5}$ and that, on a global scale, only less than $10 \%$ of the polymers produced will have undergone some type of recycling ${ }^{6}$.

Developments in the area have led to other alternatives for environmental impact reduction caused by the inappropriate disposal of polymers that are not degraded by microorganisms in a short time interval. Since 1960, the high cost associated 
with the synthesis and development of new monomers has steered scientist to develop new materials with good performance and viable costs for industrial applications. This has led to systems based on polymer blends ${ }^{7}$. The combination of properties from the individual components composing the blend as well as the requirements for specific applications, have enhanced the use of these mixtures in a wide range of applications, such as in the automotive, aeronautical and packaging sectors ${ }^{8}$. Currently, considering environmental concerns, blends that include the partial or total replacement of traditional polymers by biodegradable ones are on the rise as they not only increase their application range but also improve the resulting material's biodegradability ${ }^{9}$. An example of a polymer synthesized from renewable resources is polyhydroxybutyrate (PHB). The literature on blends that associate polymers from fossil sources with those of natural origin is vast, integrating the search for alternatives capable of combining biodegradation and recycling.

Polypropylene (PP) stands out among polymers from fossil sources that can be recycled and form blends with potential for biodegradation. PP is one of the most used industrial polymers in the world. In $2018,19 \%$ of the world's plastic production was PP. The main reasons being its low cost and good set of mechanical properties that allow a wide spectrum of applications ${ }^{10}$. Many polymers have been developed from biodegradable resources and among those, PHB is one of the most promising for blending not only due to its high rate of biodegradation - around 3 months after being buried in simulated soil - but also because its processing conditions are similar to those of conventional polymers. PHB can be produced by fermentation of bacteria or fungi and was discovered in 1920 as a storage material for carbon and intracellular energy accumulated in several microorganisms, such as the bacteria Alcaligenes eutrophus, Bacillus and Pseudomonas ${ }^{5}$. Based on demand, it is more advantageous to use it in polymer blends to provide improved properties instead of using it neat ${ }^{11}$. Some works have proposed the development of blends based on PP and PHB as a strategy to improve the biodegradation performance of the resulting material.

Santos et al. ${ }^{12}$ produced PP/PHB blends aiming at improving toughness and processability, as well as employing oxidizing additives to increase the degradability of PP after disposal. The synergistic effect that occurred in these blends was attributed to the acceleration of PHB degradation by oxidized PP. Fonseca et al. ${ }^{13}$ incorporated titanium dioxide $\left(\mathrm{TiO}_{2}\right)$ nanoparticles as a pro-degrading agent in the PP / PHB blend and observed that $\mathrm{TiO}_{2}$ was able to act as a pro-degradant and improve some of the blend's mechanical properties.

Considering that polymer mixtures tend to have immiscible morphologies due to thermodynamic limitations and that morphology strongly affects mechanical performance, compatibility becomes a fundamental concern in polymer blends. Sadi et al. ${ }^{14}$ studied the effect of several compatibilizers on the morphology and mechanical properties of PP/PHB blends and concluded that the compatibilizers efficiency decreased in this order: $\mathrm{P}(\mathrm{E}-\mathrm{MA}-\mathrm{GMA})>\mathrm{P}(\mathrm{E}-\mathrm{MA})>\mathrm{P}(\mathrm{E}-\mathrm{GMA})>$ $\mathrm{PP}-\mathrm{MAH}$, producing systems with $\mathrm{PHB}$ phase refinement, which led to superior properties. In order to improve the performance of polymer blends and meet the demands for materials with improved properties, other components, such as organophilic clays, may be added to the mixture to produce nanocomposites with improved physical and mechanical properties. Montmorillonite is the most widely used inorganic filler for the production of polymer nanocomposites. It is the main component of bentonite clay which can be chemically modified (organophilized) and incorporated into polymers by conventional processing routes. Nanocomposites usually are produced at low filler levels $(<10 \%)$. The insertion of clay in polymer systems can favor mechanical recycling cycles and help to maintain other properties of the material. However, studies on nanocomposite systems based on polymer blends are not as common.

The aim of this work was to evaluate the recyclability potential of a PP/PHB blend and its nanocomposite having an organophilic montmorillonite as reinforcement. The present work also proposes the combined use of a polar agent (Erucamide) used in the industry as a lubricating agent, in addition to PP-g-MA as a new compatibilizer system, The idea being that this system would help to better disperse the clay filler, promote greater polymer/filler compatibility and hence improve nanocomposite performance. The influence of repeated processing (up to seven extrusions) on the morphology (XRD and Scanning Electron Microscopy- SEM) and mechanical performance (tensile and impact) of the blend and nanocomposite were investigated.

\section{Experimental}

\subsection{Materials}

The PP resin used in this study was the copolymer RP 347 (Braskem S/A), with a melt index of $10 \mathrm{dg} \cdot \mathrm{min}^{-1}$ measured at $230{ }^{\circ} \mathrm{C}$ with a $2.16 \mathrm{~kg}$ weight, as per standard ASTM D1238 ${ }^{15}$, according to the manufacturers data sheet. The biodegradable polymer was PHB (PHB Industrial S/A), with a melt index of $40 \mathrm{~g} .10 \mathrm{~min}^{-1}$ at $190{ }^{\circ} \mathrm{C} / 2.16 \mathrm{~kg}$. The filler was organically modified montmorillonite, commercially known as Cloisite 20A (Southern Clay Products). The compatibilizer was PP-g-MA, a functionalized poly(propylene) (maleic anhydride-grafted propylene) manufactured by Chemtura under the commercial name of Polybond 3200, with a melt index of $115 \mathrm{dg} \cdot \mathrm{min}^{-1}$. Another additive used as a co-intercalator was cis-13-docosenamide $\left(\mathrm{C}_{22} \mathrm{H}_{43} \mathrm{NO}\right.$, molar weight $\mathrm{M}=337.6$ g. $\mathrm{mol}^{-1}$ ), commonly known as erucamide, with the commercial name of Armoslip E Powder (Akzo Nobel).

\subsection{Processing of the blend and nanocomposite}

The neat polypropylene and the PP/PHB blend were processed directly in a single-screw extruder. Processing of the nanocomposite was performed in two steps. First a PP-g-MA/Eru/organoclay masterbatch was prepared in an internal mixer followed by dilution with PP and PHB in a single-screw extruder.

Components were identified as: neat polypropylene (PP), polyhydroxybutyrate (PHB), organophilic clay (MMO), maleic anhydride grafted compatibilizing agent (gMA) and erucamide (Eru). 


\subsection{Masterbatch preparation (MMO/gMA/Eru)}

In order to promote organoclay incorporation in the polymer matrix, a masterbatch containing organophilic montmorillonite (Cloisite 20A), PP-g-MA (Polybond 3200) and erucamide was prepared in a Haake Rheomix 3000 internal mixer operating with high-intensity rollers at $190^{\circ} \mathrm{C}$ and $60 \mathrm{rpm}$ for $7 \mathrm{~min}$.

\subsection{PP/PHB/MMO/gMA/Eru nanocomposite processing}

The masterbatch obtained in the internal mixture was used to produce the nanocomposite by diluting it in $\mathrm{PP}$ and $\mathrm{PHB}$ to the desired concentration $(74.5 \% \mathrm{PP} / 15 \%$ $\mathrm{PHB} / 5 \% \mathrm{MMO} / 5 \% \mathrm{gMA} / 0.5 \% \mathrm{Eru}, \mathrm{w} / \mathrm{w}$ ) in a bench-top single-screw extruder (AX Plásticos Lab 16) operating with a temperature profile of 175,180 and $190{ }^{\circ} \mathrm{C}$, and $60 \mathrm{rpm}$ screw speed. Seven consecutive extrusion cycles were performed, and the material output of the first, third, fifth and seventh cycles was collected, pelletized and characterized.

\section{5. $\mathrm{PP} / \mathrm{PHB}$ blend processing}

PHB was dried in an oven at $60{ }^{\circ} \mathrm{C}$ for $4 \mathrm{~h}$ prior to processing. Then, PP and PHB $(85 / 15 \mathrm{w} / \mathrm{w})$ were tumble mixed and extruded under the same conditions in the equipment previously described in "PP/PHB/MMO/gMA/Eru nanocomposite processing".

\subsection{PP processing}

In order to assess the effect of recycling on its properties, PP was reprocessed for up to seven extrusion cycles under the same operational conditions and equipment previously described for the other systems for comparison purposes as $\mathrm{PP}$ is the major constituent of the blend and nanocomposite manufactured here (in a bench-top single-screw extruder (AX Plásticos Lab 16) operating with a temperature profile of 175,180 and $190{ }^{\circ} \mathrm{C}$, and $60 \mathrm{rpm}$ screw speed).

\subsection{Molding}

After being pelletized, neat PP, the polymer blend and the nanocomposite were dried in an oven at $70{ }^{\circ} \mathrm{C}$ for $7 \mathrm{~h}$ after the first and third extrusion cycles and for $24 \mathrm{~h}$ after the fifth and seventh extrusion cycles. Then, specimens were compression molded for tensile and impact strength tests according to ASTM D638 ${ }^{16}$ and ASTM D256 $6^{17}$ standards, respectively.

The images of the specimens were captured using a Smartphone Samsung, Model Galaxy J4 (13 megapixels).

\subsection{X-ray diffraction}

The degrees of crystallinity of the reprocessed neat PP, blend and nanocomposite samples were assessed by XRD (Shimadzu, model XRD 6000). The source of the incident radiation was $C u K_{a}$ with a wavelength of $0.154 \mathrm{~nm}$. Data were collected at a scanning rate of $2^{\circ} \cdot \mathrm{min}^{-1}$ and an angular range $(2 \theta)$ of 5 to $45^{\circ}$. The materials were analyzed as traction specimens. The degree of crystallinity was calculated according to the method described by Ruland ${ }^{18}$ (Equation 1):
$\% I C=\frac{I c}{\left(I c+K I_{a}\right)} \times 100$

Where $\% C$ is the percentage of crystallinity, $I_{a}$ is the area under the amorphous halo, $I_{c}$ is the result of the integration of the diffraction peaks or the area of the crystalline peaks and $K$ is a proportionality constant for each polymer, equal to 0.98 for PP and 0.96 for PHB. In order to determine the areas of the crystalline peaks and the amorphous halo, the diffractograms were deconvoluted using the Fityk computer program with a Gaussian fit.

For the blend and the nanocomposite, $I_{c}$ and $I_{a}$ have crystalline and amorphous phases corresponding to PP and PHB. Theoretical values for the degree of crystallinity (\% ICcal) were estimated by the additivity (Equation 2$)^{19}$ :

$\% I C c a l=\% I C_{P P} \cdot f_{p p}+\% I C_{P H B}\left(1-f_{p p}\right)$

This equation was used to correct the degree of crystallinity, where $f_{p p}$ is the PP weight fraction and $I C_{P P}$ and $I C_{P H B}$ are the degrees of crystallinity of PP and PHB, respectively.

\subsection{Morphological analysis}

Morphological analysis was performed by SEM on the specimens fractured in the impact tests. The device used was a Shimadzu SSX-550 operating under a nitrogen atmosphere with a tungsten filament. The samples were gold sputtered, with a current of 10-15 mA for $2 \mathrm{~min}$ per sample.

\subsection{Mechanical analysis}

Tensile tests were performed according to the ASTM D638 ${ }^{16}$ standard in a universal testing machine (EMIC model DL 30000) operating at room temperature and a displacement rate of $50 \mathrm{~mm} . \mathrm{min}^{-1}$. The results were reported as the average of six measurements. Izod impact tests were performed according to the ASTM D $256{ }^{17}$ standard in a Ceast model Resil 5.5 instrument operating with a $2.75 \mathrm{~J}$ hammer. The samples were notched to a $2.5 \mathrm{~mm}$ depth before testing. The average results for eight specimens were reported.

\subsection{Statistical Analysis}

The statistical technique of Analysis of Variance (ANOVA) was used to determine if there is a significant difference between the results presented for each composition (neat reprocessed PP, blend and nanocomposite) as a function of reprocessing cycles ( 1 to 7 ). The Tukey multiple comparison test between each pair of averages was also calculated. That is, averages were compared for each pair of compositions and for each pair of reprocessing cycles. In this study, a significance level of $5 \%$ was adopted

\section{Results and Discussion}

\subsection{Processing of the PP, the blend and the nanocomposite}

Figure 1 shows images of the reprocessed neat PP, PP/PHB (85/15) polymer blend and nanocomposite specimens, respectively. All the materials have a smooth and 
homogeneous surface. As the number of cycles increases, the color of all specimens intensifies. The neat PP specimen changes from translucid to light yellow and the blend and composite from light yellow to a brownish color. As shown
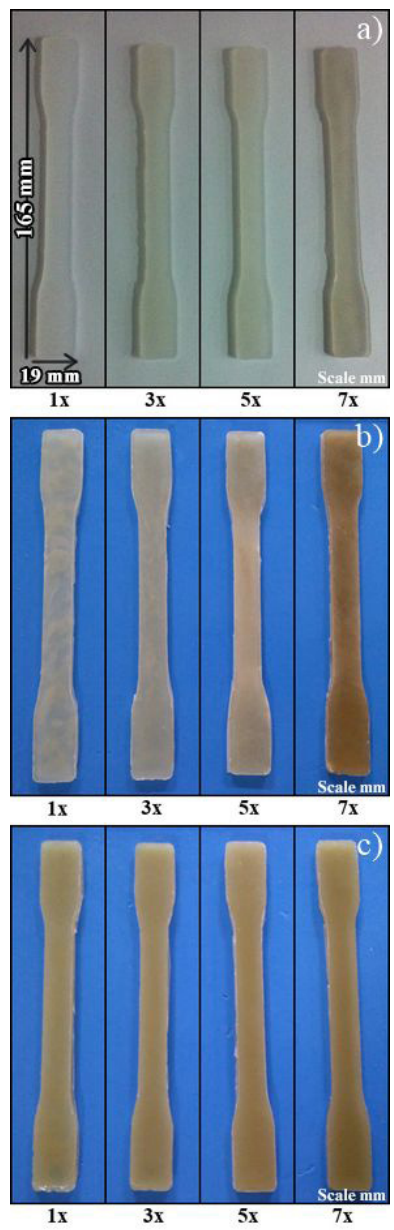

Figure 1. Reprocessed (a) pure PP, (b) PP/PHB blend and (c) nanocomposite.

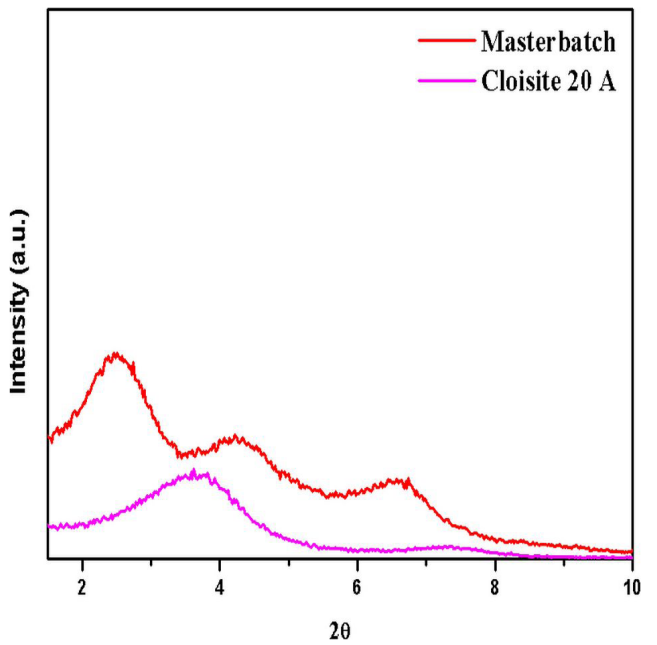

Figure 2. Clay (Cloisite 20A) and concentrate (masterbatch) of $\mathrm{MMO} / \mathrm{gMA} /$ Eru XRD patterns. in the following figure, color change is the first sign that degradation is taking place.

Polymer degradation may lead to color changes caused by chain scission and the formation of chromophores (De Paoli ${ }^{20}$ ). During extrusion, polymers are subjected to heating and shear over a period of time which may initiate degradation reactions. Yellowing is typical of thermomechanical degradation. Our results indicate that all systems investigated (neat $\mathrm{PP}$, the $\mathrm{PP} / \mathrm{PHB}$ blend and the compatibilized PP/PHB/Organoclay nanocomposite) degraded with the reprocessing cycles, which is more evident for each material after the seventh cycles. Thermal heating can cause chain scission and the formation of radicals which in turn can then abstract hydrogen from a tertiary carbon in a PP chain to generate a PP macroradical. The macroradical can undergo $\beta$ scission, which causes the formation of a double bond in the $\beta$ position resulting in a reduction in molecular weight ${ }^{21}$. This reduces the thermal and color stability of the materials, which would explain the color changes in the reprocessed systems.

The color change of the compatibilized nanocomposite with the number of extrusion cycles was slighter than those observed for PP and the blend. This was attributed to the fact that the organoclay is more thermally stable than the polymers used at the processing temperatures adopted. The PP-g-MA compatibilizer present in the nanocomposite acts of the silicate layer surfaces and chain scission of the anhydride group is reduced in the presence of montmorillonite particles.

\subsection{X-ray diffraction}

Figure 2 shows the XRD patterns obtained for the organophilic montmorillonite (Cloisite 20A) and for the masterbatch of $\mathrm{MMO} / \mathrm{gMA} /$ Eru.

The effect of the erucamide and the PP-g-MA compatibilizer on the clay structure can be observed in Figure 2. The influence of polymer intercalation on the arrangement of silicate layers is indicated by changes in the intensity, shape and peak positions of basal reflections. Here, a shift of the main peak of the organoclay to smaller angles was observed. This is taken as an indication that the polymer chains were introduced between the lamellae of Cloisite 20A clay resulting in an increase of the basal interplanar distance d (001) from $2.43 \mathrm{~nm}$ to $3.59 \mathrm{~nm}$. These results correspond to the formation of an intercalated structure at this stage of processing, which facilitates the formation of a dispersed phase nanocomposite. These results are in agreement with those of Alves et al. ${ }^{22}$, who investigated the influence of different contents of PP-g-MA and erucamide on the characteristics of PP/clay nanocomposites. Those authors observed that the PP-g-MA incorporation led to an increase in the basal interplanar distance of all composites and that intercalated structures were obtained.

Ratnayake et al. ${ }^{23}$ also observed increases in the basal interplanar distance and the appearance of the second peak in composites based on poly(propylene), organophilic clay, a PP-g-MA compatibilizer and erucamide. These authors reported that at low quantity the erucamide molecules are trapped inside the clay and do not migrate to the surface.

Figure 3 shows the XRD patterns of pure PP, the PP/PHB blend and the $\mathrm{PP} / \mathrm{PHB} / \mathrm{MMO} / \mathrm{gMA} /$ Eru nanocomposite after each reprocessing condition. 

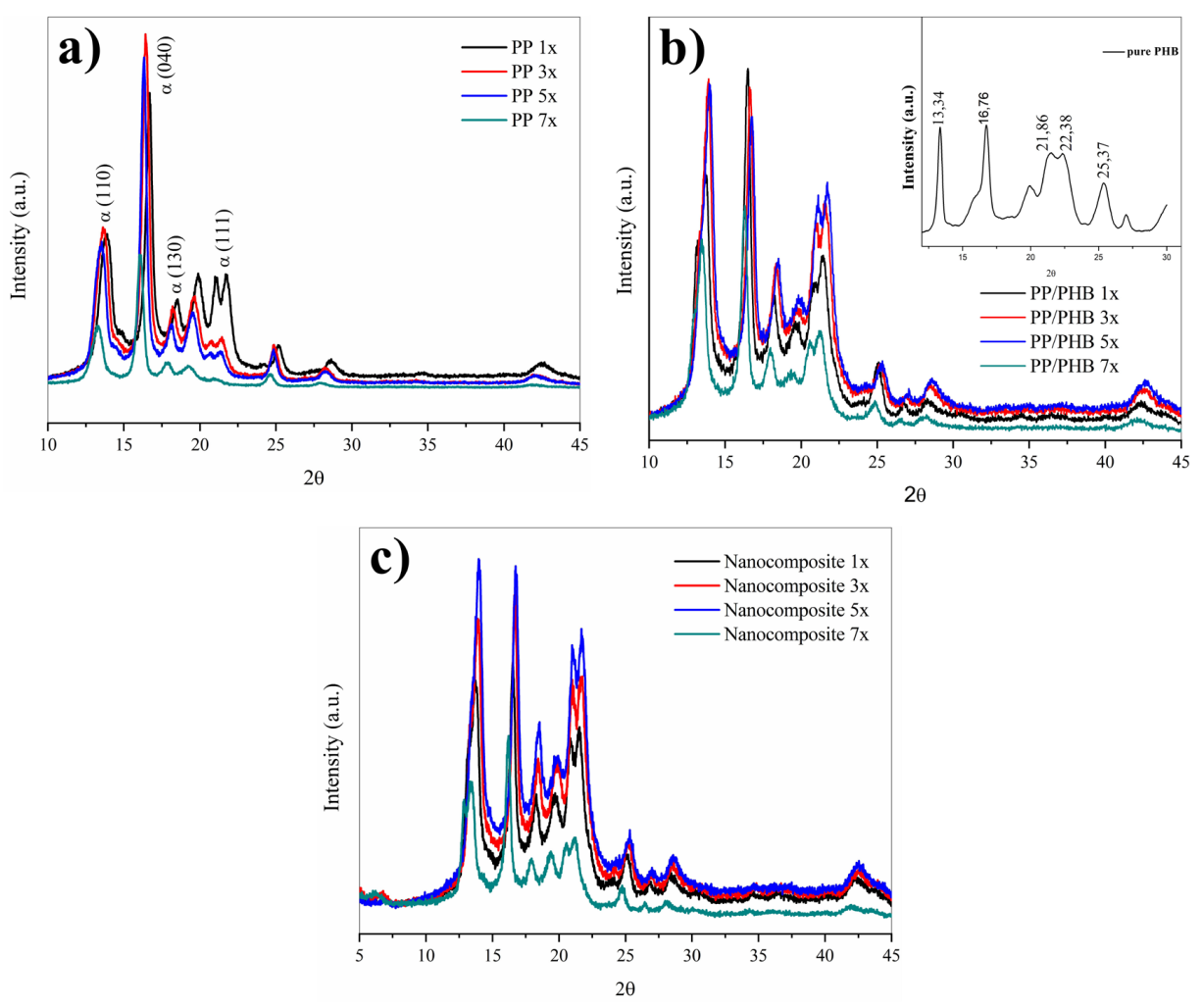

Figure 3. XRD patterns of pure PP, the PP/PHB blend and the PP/PHB/MMO/gMA/Eru nanocomposite after each reprocessing condition.

Table 1. Effects of reprocessing cycles on the degree of crystallinity of the systems investigated.

\begin{tabular}{|c|c|c|c|}
\hline \multirow{2}{*}{ Cycle } & Neat PP & Blends & Nanocomposites \\
\hline & Crystallinity $(\% \mathrm{IC})$ & Crystallinity $(\% \mathrm{IC})$ & Crystallinity (\%IC) \\
\hline 1 cycle & $52.73 \mathrm{a}$ & $50.79 \mathrm{~b}$ & $49.70 \mathrm{~b}$ \\
\hline 3 cycles & $57.43 \mathrm{a}$ & $54.34 \mathrm{~b}$ & $51.45 \mathrm{~b}$ \\
\hline 5 cycles & $58.64 \mathrm{a}$ & $54.93 \mathrm{~b}$ & $52.82 \mathrm{~b}$ \\
\hline 7 cycles & $56.69 \mathrm{a}$ & $49.68 \mathrm{~b}$ & $49.54 \mathrm{~b}$ \\
\hline
\end{tabular}

Averages having the same index are not statistically diferente among each other according to the Tukey test t $5 \%$ probability.

The diffraction patterns of the neat PP shows the presence of monoclinic crystals characteristic of the PP alpha form, with peaks at $2 \theta: 13.82^{\circ}, 16.66^{\circ}, 18.44^{\circ}$ and $21.70^{\circ}$, corresponding to planes (110), (040), (130) and (111), respectively ${ }^{24-27}$. Reprocessing did not result in nucleation of the beta and gamma phases of PP which are associated to the impact strength of this polymer. However, as the number of extrusion cycles increased, a reduction in the intensity of the diffraction peaks of neat PP as well as a displacement to lower angles was observed. This shows that the amorphous portion of polypropylene under the adopted processing conditions is reduced and indicates that thermomechanical degradation reduces the polymer molar mass, favors spherulitic nucleation and affects crystal morphology ${ }^{28}$. Figure 4 shows the diffractograms of the reprocessed PP/PHB blend and of the neat PHB before the reprocessing cycles (upper right corner).

In the case of the PP/PHB blend, the diffraction peaks for PP were found at $2 \theta: 13.54^{\circ}, 16.43^{\circ}, 18.17^{\circ}$ and $21.34^{\circ}$, and for the $\mathrm{PHB}$, two intense peaks are observed at $2 \theta$ equal to $13.30^{\circ}$ and $16.76^{\circ}$ and peaks of intermediate intensities $21.86^{\circ}, 22.38^{\circ}$ and $25.37^{29-31}$. According to Thire et al.$^{29}$, the diffraction profile of neat PHB sample shows well-defined peaks at $2 \theta$ equal to $13.6^{\circ}, 17.1^{\circ}, 21.7^{\circ}, 22.7^{\circ}$ and $25.6^{\circ}$, corresponding to, respectively, reflections (020), (110), (101), (111) and (121) of the orthorhombic unit cell of PHB.

Peaks similar to those of the neat PP and the blend are observed in the nanocomposite diffractogram. The XRD diffractograms of all the materials investigated show welldefined peaks and no significant changes in the positions of the peaks with reprocessing cycles. An increase in the intensity of the peaks from the first to fifth cycles and a reduction of the intensity in the seventh cycle of reprocessing is observed. This behavior may be related to a change in the materials crystallinity. To investigate possible changes in the materials crystallinity, a deconvolution of the crystalline peaks was performed, and the degree of crystallinity was calculated by the Ruland method. The results obtained are shown in Table 1.

Our data shows that, in general, the degree of crystallinity depended on number of extrusion cycles and system composition. According to the results of 

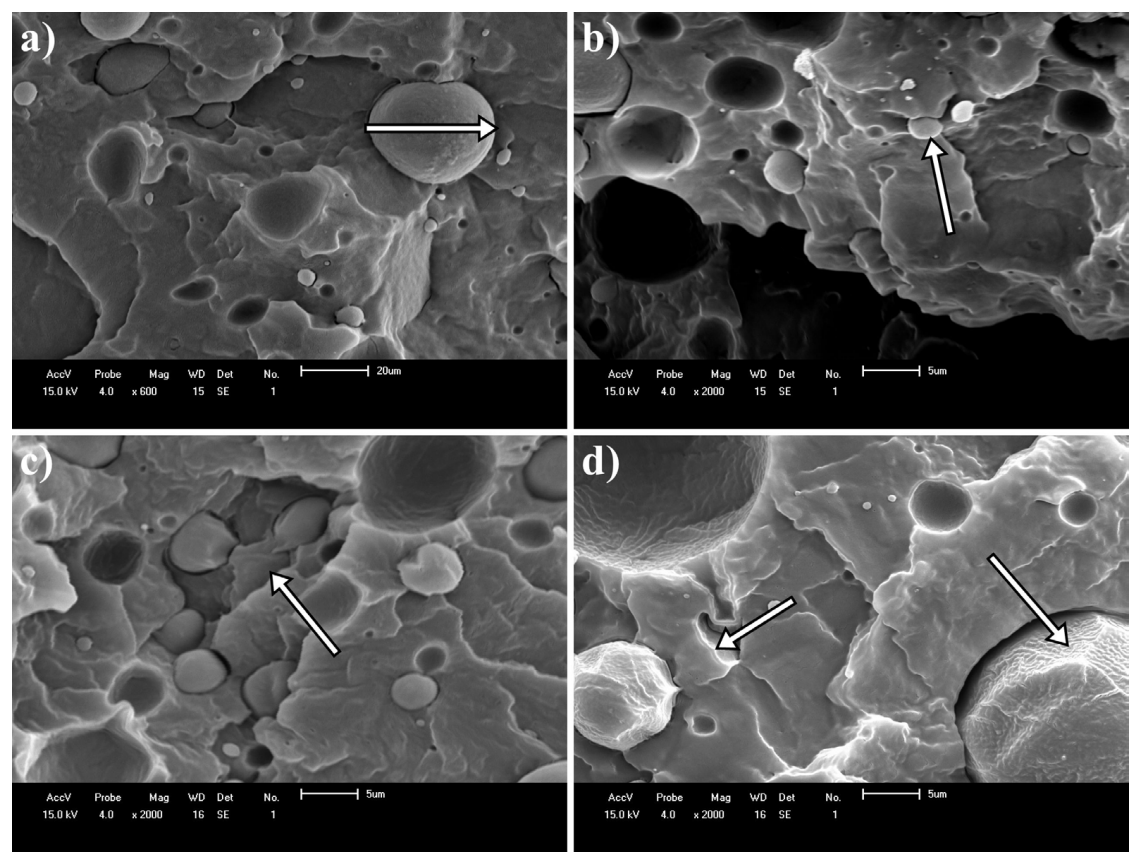

Figure 4. Micrographs of the blend with 1 reprocessing cycle (a), with 3 reprocessing cycles (b), with 5 reprocessing cycles (c) with 7 reprocessing cycles $(\mathrm{d})$.

ANOVA and Tukey's test, there is a significant difference in the crystallinity index values $(\% \mathrm{C})$ between neat PP and the blend ( $\mathrm{p}$-value $<0.05$ ) and between neat PP and nanocomposite (p-value) $<0.05$ ). Among the three formulations, neat PP had the highest degree of crystallinity in all extrusion cycles. Table 1 shows slight crystallinity increases until the fifth cycle and that a crystallinity reduction is observed in the seventh cycle for all systems investigated. The differences in the mean degree of crystallinity between the seventh cycle and cycles 1 , 3 and 5 are not significant ( $p$-values $>0.05$ ). The increase in crystallinity can be attributed to thermomechanical degradation of PP and PHB chains resulting in chain scission, a reduction in polymer molar mass resulting in increased chain mobility and crystallization during cooling. The shorter polymer chains can form crystals more easily and thus the crystallinity increases. This increase in crystallinity with reprocessing is consistent with the literature ${ }^{32-38}$ and this phenomenon is also known as chemicrystallization process.

For comparison, the crystallinity of unprocessed neat PHB was calculated according to the Ruland method, and a degree of crystallinity of $66.7 \%$, in agreement with the literature ${ }^{39}$ was obtained, which indicates that the method adopted leads to trustworthy results. The results in this work indicated that the neat polymers have a higher crystallinity than the mixtures (blend and nanocomposite). That is, the addition of materials to the polymer matrices reduces crystallinity, which is in agreement with the findings in the literature.

The crystallinity reduction observed in the seventh reprocessing cycle may be associated to excessive thermomechanical degradation of the materials were reprocessed seven times.

\subsection{Scanning electron microscopy}

Figure 4 shows the micrographs of the reprocessed blend. The images are of the fractured surfaces of the specimens, with 2000x magnification.

The micrographs shows two phases: a continuous one of PP and a dispersed one with spheroidal morphology (indicated by arrows), considered to be the PHB phase. Therefore, its phase assumes a spherical form, which is more stable because of the lower surface tension and is kept dispersed in the PP matrix.

The PP/PHB mixture had a morphology typical of an immiscible mixture with a weak adhesion between the phases which is attributed to differences in polarity and chemical structure. The voids that appear in the micrograph are a result of the separation of the blend components when the impact force is applied, an indication of a weak interphase interaction ${ }^{40,41}$.A similar behavior was reported by Pachekoski et al. ${ }^{42}$, who examined PHB/PP mixtures after processing. Other studies report the immiscibility of polymer blends of morphologies similar to the one found in this research ${ }^{40,43-45}$.

It can be observed that the size of the PHB phase increases with the number of reprocessing cycles, which is more visible in the seventh cycle (Figure 4d). These results are thought to indicate that the intense shear causes the coalescence of the PHB phase in the blend.

Figure 5 shows the micrographs of the reprocessed nanocomposite. The images are of the fractured surfaces of the specimens, with 2000x magnification.

Different from the blend, the nanocomposite exhibited a more homogeneous morphology with a significant reduction of the size of the PHB phase. It was still possible to observe small voids characteristic of PHB in the first cycle. However, 

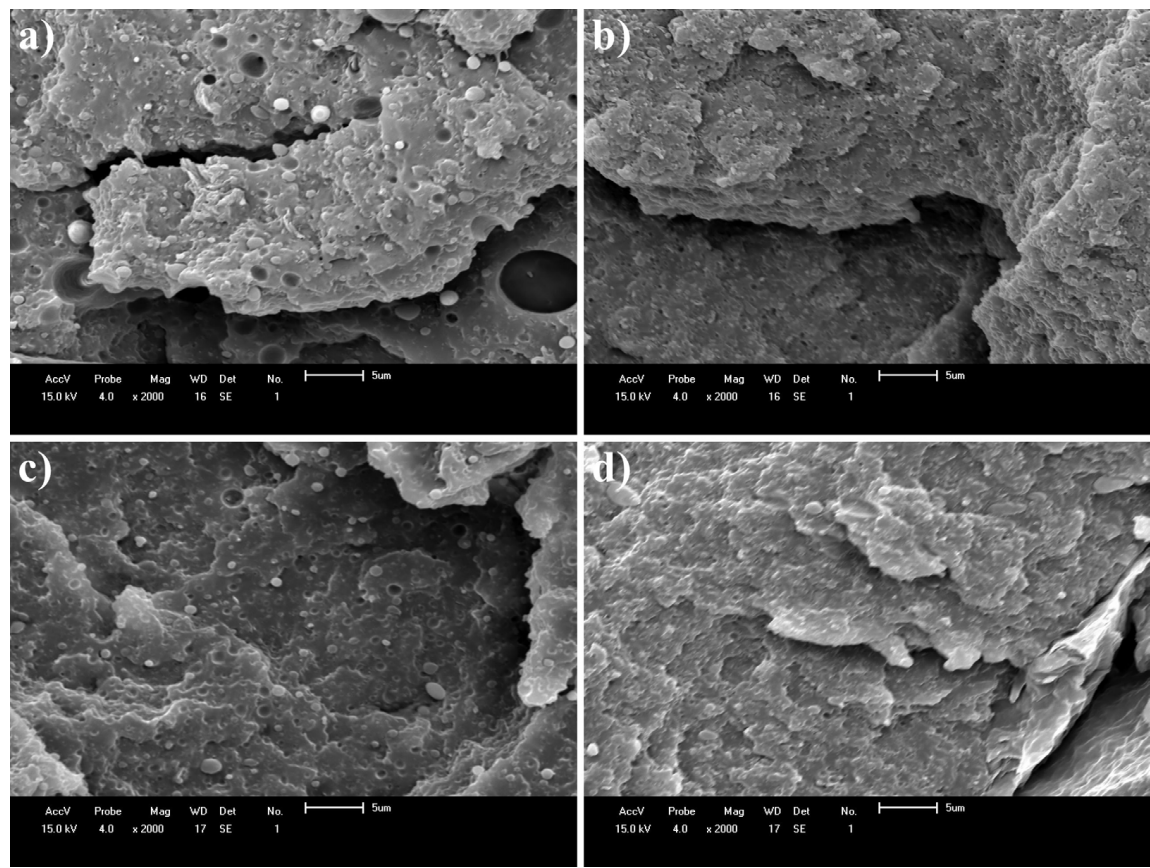

Figure 5. Micrographs of the nanocomposite with 1 reprocessing cycle (a), with 3 reprocessing cycles (b), with 5 reprocessing cycles (c) with 7 reprocessing cycles (d).

the morphology becomes more homogeneous with the additional reprocessing cycles until the PHB dominions in the mixture are nearly imperceptible in the micrographs. The changes in nanocomposite morphology are related to the incorporation of organophilic clay, primarily through the action of the compatibilizer and the erucamide, which were added to improve the interaction of the clay with the polymer matrices. This addition reduced the size of the different phases, as shown in the micrographs. Similar results regarding the reduction of the domains in the blend were reported by Anadão ${ }^{46}$, Coelho and Morales ${ }^{47}$ and Ferreira et al. ${ }^{48}$ when a single compatibilizer was used.

Here, it could be observed that for both the blend and the nanocomposite there was no significant change in the morphology over the cycles. There was a reduction of the domains of the different phases but, in general, reprocessing did not change the morphology of the recycled material. The main difference here is that a second additive, erucamide, commonly used as lubricants in the production of polymeric films, was used and seemed to enhanced the compatibility between the components. That is, the compatibilizer improved the adhesion of the phases, which resulted in the reduction of the size of the PHB-rich phase and the control of the size distribution of the dispersed phase.

\subsection{Mechanical properties}

The mechanical properties of polymer systems can be influenced by factors such as processing conditions, molecular weight, degree of crystallinity, composition and the polymer/filler interaction. In our study, the organoclay acts as the reinforcement, and the filler/matrix interaction of the nanocomposite has a strong influence on the characteristics of their interface ${ }^{49}$. Figure 6 and 7 shows the values of tensile

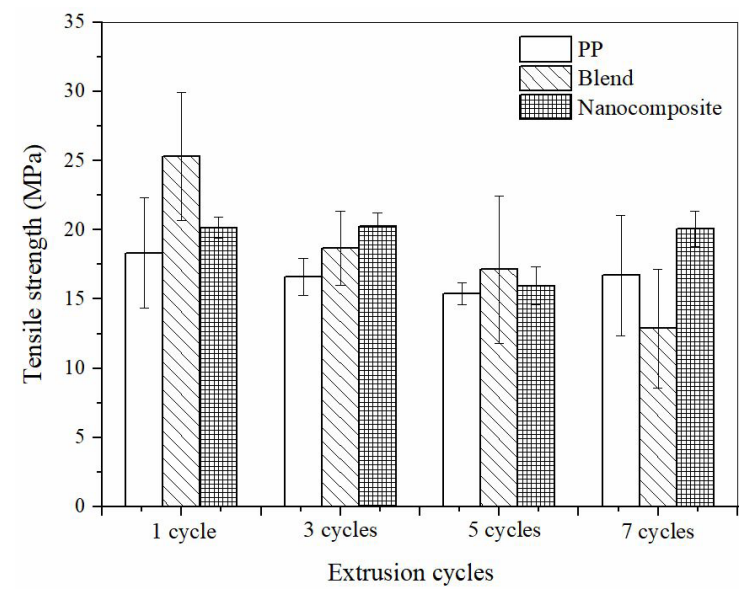

Figure 6. Tensile strength at break.

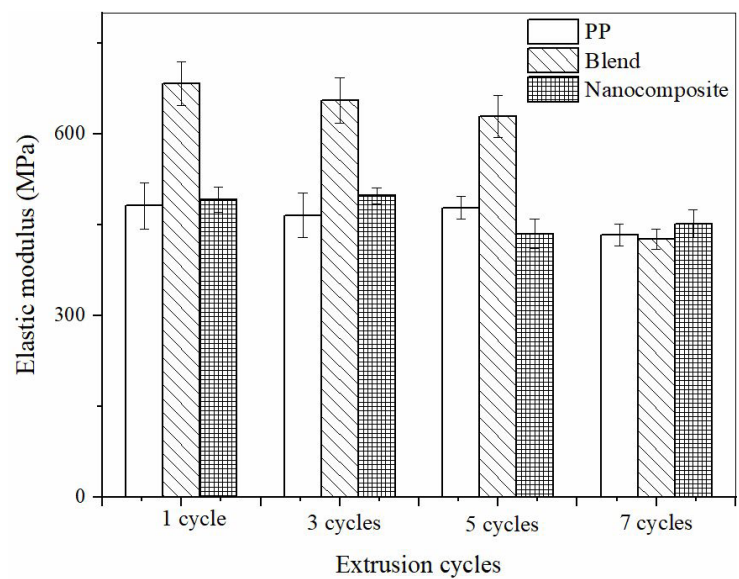

Figure 7. Elastic modulus. 
strength at break and elastic modulus obtained from the tensile tests of the reprocessed pure PP, blend and nanocomposite.

Tensile test results indicate that the number of extrusion cycles generally had little influence on the mechanical properties of PP. The values were similar over the reprocessing, $(p$-value $>0,05)$ and cycles ( $p$-value $>0,05)$, with a slight reduction in the number of cycles. For the nanocomposite, the incorporation of clay, PP-g-MA, and erucamide in the blend resulted in a small increase in the strength at break compared to that of neat PP and the blend. The change in nanocomposite morphology may have influenced the materials mechanical properties, considering that they are more homogeneous than the blends.

In addition, considering the experimental spread, the values remained practically unchanged over the reprocessing cycles, except for the fifth cycle, which had the lowest value. In the case of the blend, after considering the experimental error, the first cycle had the highest values, which decreased with the further reprocessing. This reduction can be explained by chain scission caused by degradation undergone by the blend during reprocessing. Tensile strength is one of the properties most strongly affected by chain scission promoted by consecutive extrusion cycles. The reason for this is that chain scission occurs at the amorphous regions, where ties molecules are located in semicrystalline polymers and these molecules are the ones responsible for the mechanical integrity of semicrystalline polymers ${ }^{50}$.

The elastic modulus is associated with stiffness. That is, the higher that the modulus is, the more rigid the system. Figure 7 shows that the elastic modulus of neat PP remains unchanged until the fifth cycle and only decreases on the seventh extrusion. Since color did change which indicates that chain scission was taking place, this is attributed to an increase in PP crystallinity, making the material more rigid and compensating for a reduction in molar mass. This indicates that thermomechanical degradation is controlled by both an increase in crystallinity increase and the insertion of defects in the amorphous chains $\mathrm{s}^{34,51-53}$.

A reduction of the elastic modulus of the pure polymer is observed in the seventh cycle, which can be explained by the observed reduction in the degree of crystallinity determined by XRD. Oliveira et al. ${ }^{28}$ suggested that a reduction of the interaction between the amorphous and the crystalline phases reduces the stiffness of consecutively reprocessed poly(propylene).

The blend had a much higher elastic modulus than neat PP ( $p$-value $<0,05)$. The material becomes more rigid with PHB incorporation, and although the stiffness decreases with the number of reprocessing cycles, the values are still higher than those of neat PP for all the cycles. Considering that the crystallization temperature of PHB is close to room temperature, its degree of crystallinity increases with time, which restricts the mobility of the amorphous phase and turns PHB brittle ${ }^{54}$. This brittleness may cause the increase in elastic modulus of the polymer blend.

Therefore, the elastic modulus and the degree of crystallinity linearly increase. That is, the stiffness of the material increases with increasing crystallinity. The XRD analyses shows a crystallinity increase until the fifth reprocessing cycle of all the materials. Therefore, the increase in the materials stiffness corroborates the increase in crystallinity observed in the compounds.

For the nanocomposite, there was a small increase in the elastic modulus of the reprocessed materials compared to that of the neat polymer. This increase, however, was not significant ( $\mathrm{p}$-value $>0,05$ ). Botana et al. ${ }^{55}$ developed nanocomposites with $\mathrm{PHB}$ and montmorillonite prepared by melt intercalation. The authors noted that the use of organo-modified clay resulted in an increase in crystallinity and a decrease in the size of the spherulites and that this morphology contributed to increasing the elastic modulus of the system.

Moreira et al. ${ }^{49}$ assessed the effect of compatibilizers and a co-intercalator on the morphology and mechanical behavior of poly(propylene)/organophilic clay at different proportions. The authors observed that the nanocomposites with $\mathrm{PP} / 5 \mathrm{~A} / 5 \mathrm{MA} / 0.5 \mathrm{E}$ displayed an increase in their elastic modulus compared to the pure polymer and attributed this outcome to better filler dispersion and structural type. The effect of the addition of the compatibilizer (PP-g-MA) and of the co-intercalator (erucamide) to maximize the compatibility between the filler and the polymer matrix in PP/organophilic clay systems was investigated by Silva et al. ${ }^{56}$.

Alves et al. ${ }^{22}$ studied nanocomposites based on polypropylene homopolymer/organophilic clay in the presence of PP-g-MA and erucamide at different proportions. Authors noted that the elastic modulus of PP-g-MA/PP blends was higher than that of the neat homopolymer and that the addition of clay and compatibilizer led to an increase in the elastic modulus compared to that of the PP/PP-g-MA blend. This outcome indicated that the addition of compatibilizer enhanced polymer/clay interaction through a higher intercalation in the clay. The same authors noted discrete increases in the elastic modulus of the systems with the incorporation of erucamide. They also noted that the tensile strength was affected by the incorporation of clay, compatibilizer and co-intercalator, although with less intensity. Low contents of organoclay incorporation together with the compatibilizer helped to maintain the tensile properties of the reprocessed systems.

Figure 8 shows the impact strength values for the neat PP, blend and nanocomposite as a function of extrusion cycles. Results indicate that there was a significant difference

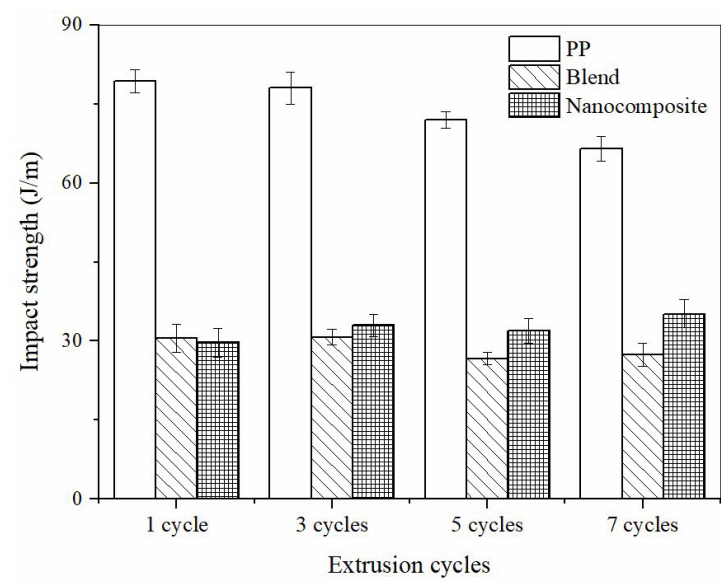

Figure 8. Impact strength. 
between the impact strength of the neat reprocessed PP and those of the blend and nanocomposite $(\mathrm{p}<0,05)$.

The data obtained showed that only neat polypropylene had a non-significant reduction in impact strength ( $\mathrm{p}$-value $>$ 0.05) up to five extrusion cycles. The impact strength of the blend was significant lower than that of PP which was attributed to low compatibility of the blend as well as to the incorporation of a rigid PHB phase. Reprocessing hardly changed the blend's impact strength.

As expected, the impact strength of the nanocomposite was lower than neat PP, which was attributed to the organoclay reducing the mobility of the polymer molecules ${ }^{57}$. The impact strength of the nanocomposites was higher than that of the blend, particularly at higher reprocessing cycles. It was expected that filler addition would lead to stiffening of the system and lower impact strength. The observed behavior is attributed to the finer morphology and reduced crystallinity as observed by SEM and XRD.

In summary, the properties of the nanocomposite were not changed or displayed insignificant losses with the number of cycles, which indicates the excellent stability of these materials. Similar results were reported by Touati et al. ${ }^{58}$ and Thompson et al. ${ }^{59}$, who assessed the influence of four reprocessing cycles of PP/PP-g-MA/Cloisite 15A nanocomposites in an internal mixer operating for $10 \mathrm{~min}$ at $50 \mathrm{rpm}$. According to those authors, the increase in the number of reprocessing cycles did not significantly affect the mechanical properties of the nanocomposites, and the dispersion improved with the number of cycles. The matrix exhibited the opposite behavior and suffered intense degradation in the fourth cycle.

Our data indicates that he addition of clay and compatibilizer to nanocomposites is benficial and is reflected in the discrete improvement or preservation of the mechanical properties after reprocessing.

\section{Conclusions}

APP/PHB blend and a nanocomposite based on this blend were extruded for up to 7 times and the effect of reprocessing on their morphology and mechanical performance was investigated. Reprocessing led to an increase in crystallinity up to the fifth cycle and the SEM analysis revealed the typical morphology of immiscible blends with two phases. The nanocomposite displayed a reduction on the size of the dispersed phase which was associated with the influence of the clay, compatibilizer and lubricant (erucamide). The blend showed greater variation in stiffness compared to the other compositions investigated up to the fifth extrusion cycle. The toughness of the blend and nanocomposite was significantly lower than that of neat PP and did not significantly change with consecutive extrusions. Our data indicates that the $\mathrm{PP} / \mathrm{PHB}$ blend and nanocomposite obtained are viable for recycling purposes as their properties did not significantly change with up to seven reprocessing cycles.

\section{Acknowledgements}

The authors thank the Postgraduate Program in Materials Engineering, Federal Institute of Piauí, Laboratory of Polymers and Conjugated Materials of the Federal University of Piauí for the physical structure and National Council for Scientific and Technological Development (CNPq) for financial support (Process: 446530/2014-0, 306312/2015-8 and 446655/2014-7). This research did not receive any specific grant from funding agencies in the public, commercial, or not-for-profit sectors.

\section{References}

1. Lebreton L, Andrady A. Future scenarios of global plastic waste generation and disposal. Palgrave Commun. 2019;5(6):1-11.

2. Cruz Sanchez FA, Boudaoud H, Hoppe S, Camargo M. Polymer recycling in an open-source additive manufacturing context: mechanical Issues. Additive Manufacturing. 2017;17:87-105.

3. Santagata C, Iaquaniello G, Salladini A, Agostini E, Capocelli M, De Falco M. Production of low-density poly-ethylene (LDPE) from chemical recycling of plastic waste: process analysis. J Clean Prod. 2020;253:1-11. http://dx.doi.org/10.1016/j. jclepro.2019.119837.

4. Fraga SCL. Reciclagem de materiais plásticos: aspectos técnicos, econômicos, ambientais e sociais. São Paulo: Editora Érica; 2014.

5. Yeo JCC, Muiruri JK, Thitsartarn W, Li Z, He C. Recent advances in the development of biodegradable PHB-based toughening materials: approaches, advantages and applications. Mater Sci Eng C Mater Biol Appl. 2018;1:1092-116.

6. Valerio O, Muthuraj R, Codou A. Strategies for polymer to polymer recycling from waste: current trends and opportunities for improving the circular economy of polymers in South America. Current Opinion in Green and Sustainable Chemistry. 2020;25:100381.

7. Mishra J, Tiwari SK, Abolhasani MM, Azimi S, Nayak GC. Fundamental of polymer blends and its thermodynamics. In: Mishra RK, Thomas S and Kalarikkal N, editors. Micro and nano fibrillar composites (MFCs and NFCs) from polymer blends. Dhanbad: Elsevier; 2017. p. 27-55.

8. Yang J, Qi X, Zhang N, Huang T, Wang Y. Carbon nanotubes toughened immiscible polymer blends. Composites Communications. 2018;7:51-64.

9. Faria AU, Martins-Franchetti SM. Biodegradation of Polypropylene (PP), Poly(3-hydroxybutyrate) (PHB) Films and PP/PHB blend by microorganisms from Atibaia. Polímeros. 2010;20:141-7.

10. Shubhra QTH, Alam AKMM, Quaiyyum MA. Mechanical properties of polypropylene composites: a review. J Thermoplast Compos Mater. 2013;26(3):362-91.

11. Plavec R, Hlavacikova S, Omaníkova L, Feranc J, Vanovcanova Z, Tomanova $\mathrm{K}$, et al. Recycling possibilities of bioplastics based on PLA/PHB blends. Polym Test. 2020;92:1-12.

12. Santos PA, Oliveira MN, Paoli MA, Freitas VG, Rosa DS Avaliação do efeito pró-oxidante no PP, em blendas com PHB, Polímeros. 2013;23:432-9.

13. Fonseca FMC, Patricio PSO, Souza SD, Orefice RL. Prodegradant effect of titanium dioxide nanoparticulates on polypropylenepolyhydroxybutyrate blends. Recycling possibilities of bioplastics based on PLA/PHB blends. J Appl Polym Sci. 2018;135(33):1-8. http://dx.doi.org/10.1002/app.46636.

14. Sadi RK, Kurusu RS, Fechine GJM, Demarquette NR. Compatibilization of polypropylene/poly(3-hydroxybutyrate) blends. J Appl Polym Sci. 2012;123(6):3511-9. http://dx.doi. org/10.1002/app.34853.

15. ASTM: American Society for Testing and Materials. ASTM D1238: Standard Test Method for Melt Flow Rates of Thermoplastics by Extrusion Plastometer. West Conshohocken: ASTM; 2020.

16. ASTM: American Society for Testing and Materials. ASTM D638: Standard Test Method for Tensile Properties of Plastics. West Conshohocken: ASTM; 2014.

17. ASTM: American Society for Testing and Materials. ASTM D256: Standard Test Methods for Determining the Izod Pendulum 
Impact Resistance of Plastics. West Conshohocken: ASTM; 2018.

18. Wunderlich B. Macromolecular physics. Vol. 1. New York: Academic Press; 1973.

19. Gedde UW. Polymer physics. London: Chapman and Hall; 1995.

20. De Paoli M-A. Degradação e estabilização de polímeros. São Paulo: Artlibe; 2009.

21. Delva L, Ragaert K, Degrieck J, Cardon L. The Effect of Multiple Extrusions on the Properties of Montmorillonite Filled Polypropylene. Polymers (Basel). 2014;6(12):2912-27. http:// dx.doi.org/10.3390/polym6122912.

22. Alves TS, Barbosa R, Angrizani CC, Coutinho MG, Carvalho LH, Canedo EL. Efeito do Co-Intercalante CIS-13-Docosenamida na morfologia e propriedades mecânicas de compósitos polipropileno/argila organofílica. Polímeros. 2013;23(5):672-7. http://dx.doi.org/10.4322/polimeros.2013.011

23. Ratnayake UN, Haworth B, Hourston DJJ. Preparation of polypropylene-clay nanocomposites by the co-intercalation of modified polypropylene and short-chain amide molecules. J Appl Polym Sci. 2009;112(1):320-34.

24. Bezerra EB, Araújo EM, Leite AMD, Mélo TJA. Obtenção e caracterização de membranas obtidas a partir de blendas poliméricas de poliamida 6. Polímeros Ciência e Tecnologia. 2014;24(3):381-7.

25. Ania F, Baltá-Calleja FJ, Flores A, Michler GH, Scholtyssek S, Khariwala D, et al. Nanostructure and crystallization phenomena in multilayered films of alternating iPP and PA6 semicrystalline polymers. Eur Polym J. 2012;48(1):86-96.

26. Wang K, Addiego F, Bahlouli N, Ahzi S, Rémond Y, Toniazzo $\mathrm{V}$, et al. Analysis of thermomechanical reprocessing effects on polypropylene/ethylene octene copolymer blends. Polym Degrad Stabil. 2012;97(8):1475-84.

27. Machado G, Denardin ELG, Kinast EJ, Gonçalves MC, de Luca MA, Teixeira SR, et al. Crystalline properties and morphological changes in plastically deformed isotatic polypropylene evaluated by X-ray diffraction and transmission electron microscopy. Eur Polym J. 2005;41(1):129-38.

28. Oliveira TA, Oliveira RR, Barbosa R, Azevedo JB, Alves TS. Effect of reprocessing cycles on the degradation of PP/PBATthermoplastic starch blends. Carbohydr Polym. 2017;168:52-60.

29. Thiré RMSM, Ribeiro TAA, Andrade CT. Effect of starch addition on compression-molded poly (3-hydroxybutyrate)/ starch blends. J Appl Polym Sci. 2006;100(6):4338-47.

30. Škrbić Z, Divjaković V. Temperature influence on changes of parameters of the unit cell of biopolymer PHB. Polymer (Guildf). 1996;37(3):505-7.

31. Sakamoto FC. Obtenção e caracterização de filmes de PHB utilizando a técnica de solution blow spinning [dissertação]. Ilha Solteira: Universidade Estadual Paulista "Júlio de Mesquita Filho", 2013.

32. La Mantia FP. Mechanical properties of recycled polymers. Macromol Symp. 1999;147(1):167-72.

33. Martins MH, De Paoli M-A. Polypropylene compounding with post-consumer material: II. Reprocessing. Polym Degrad Stabil. 2002;78(3):491-5.

34. Guerrica-Echevarría G, Eguiazábal JI, Nazábal J. Effects of reprocessing conditions on the properties of unfilled and talcfilled polypropylene. Polym Degrad Stabil. 1996;5(3):1-8.

35. González-González VA, Neira-Velázquez G, Angulo-Sánchez JL. Polypropylene chain scissions and molecular weight changes in multiple extrusion. Polym Degrad Stabil. 1998;60(1):33-42.

36. Canevarolo SV. Chain scission distribution function for polypropylene degradation during multiple extrusions. Polym Degrad Stabil. 2000;70(1):71-6.

37. Gahleitner M, Wolfschwenger J, Bachner C, Bernreitner K, Neiß1 W. Crystallinity and mechanical properties of PP-homopolymers as influenced by molecular structure and nucleation. J Appl Polym Sci. 1996;61(4):649-57.

38. Rivas LF, Casarin AS, Nepomuceno NC, Alencar MI, Agnelli JAM, Medeiros ES, et al. Reprocessability of PHB in extrusion: ATR-FTIR, tensile tests and thermal studies. Polímeros. 2017;27(2):122-8.

39. Galego N, Rozsa C, Sánchez R, Fung J, Analía Vázquez, Santo Tomás J. Characterization and application of poly ( $\beta$-hydroxyalkanoates) family as composite biomaterials. Polym Test. 2000;19(5):485-92.

40. Fonseca FMC, Patricio P, Oréfice RL. Efeito da incorporação de nanopartículas de $\mathrm{TiO} 2$ na estrutura e propriedades de blendas de polipropileno e poli(hidroxibutirato) submetidas a testes de envelhecimento acelerado. Polímeros Ciência e Tecnologia. 2014;24(3):395-401.

41. Choudhary P, Mohanty S, Nayak SK, Unnikrishnan L. Poly(Llactide)/polypropylene blends: evaluation of mechanical, thermal, and morphological characteristics. J Appl Polym Sci. 2011;121(6):3223-37.

42. Pachekoski WM, Agnelli JAM, Belem LP. Thermal, mechanical and morphological properties of poly (hydroxybutyrate) and polypropylene blends after processing. Mater Res. 2009;12(2):15964.

43. Ploypetchara N, Suppakul P, Atong D, Pechyen C. Blend of polypropylene/poly (lactic acid) for medical packaging application: physicochemical, thermal, mechanical, and barrier properties. Energy Procedia. 2014;56:201-10.

44. Nascimento WA, Lima JCC, Agrawal P, Lira HL, Mélo TJA. Blendas de PP/PA6: efeito da concentração de PA6 e compatibilizantes reativos nas propriedades mecânicas, térmicas e morfológicas. Revista Eletrônica de Materiais e Processos. 2013;8:155-62.

45. Oliveira RVB, Ferreira CI, Peixoto LJF, Bianchi O, Silva PA, Demori R, et al. Mistura polipropileno/poliestireno: um exemplo da relação processamento-estrutura-propriedade no ensino de polímeros. Polímeros. 2013;23(1):91-6.

46. Anadão P. Tecnologia de nanocompósitos: polímero/argila. São Paulo: Artliber; 2012.

47. Coelho PHS, Morales AR. The effect of organophilic montmorillonite on compatibilization, morphology and mechanical and thermal properties of PA6/ LDPE blends. Polímeros. 2013;23:410-6.

48. Ferreira KRM, Leite IF, Siqueira AS, Raposo CMO, Carvalho LH, Silva SML. Uso de argila organofílica na compatibilização de misturas PP/EPDM. Polímeros. 2011;21(5):421-8. Polímeros. 2011;21:421-8.

49. Moreira JFM, Alves TS, Barbosa R, de Carvalho ÉM, Carvalho LH. Effect of Cis-13-docosenamide in the Properties of Compatibilized Polypropylene/Clay Nanocomposites. Macromol Symp. 2016;367(1):68-75.

50. Rabello MS, White JR. Crystallization and melting behavior of photodegraded polypropylene - I. Chemicrystallization. Polymer (Guildf). 1997;38(26):6379-87.

51. Wang K, Addiego F, Bahlouli N, Ahzi S, Rémond Y, Toniazzo $\mathrm{V}$, et al. Analysis of thermomechanical reprocessing effects on polypropylene/ethylene octene copolymer blends. Polym Degrad Stabil. 2012;97(8):1475-84.

52. Aurrekoetxea J, Sarrionandia MA, Urrutibeascoa I, Maspoch ML. Effects of recycling on the microstructure and the mechanical properties of isotactic polypropylene. J Mater Sci. 2001;36(11):2607-13.

53. da Costa HM, Ramos VD, de Oliveira MG. Degradation of polypropylene (PP) during multiple extrusions: thermal analysis, mechanical properties and analysis of variance. Polym Test. 2007;26(5):676-84.

54. Quental AC, Carvalho FP, Tada ES, Felisberti MI. Blends of PHB and its copolymers: miscibility and compatibility. Quim Nova. 2010;33(2):438-46. 
55. Botana A, Mollo M, Eisenberg P, Torres Sanchez RM. Effect of modified montmorillonite on biodegradable PHB nanocomposites. Appl Clay Sci. 2010;47(3-4):263-70.

56. Silva JE No, Almeida TG, Leite RCN, Carvalho LH, Alves TS. Effect of propylene-graft-maleic anhydride and the cointercalant cis-13-docosenamide on the structure and mechanical properties of PP/organoclay clay systems. In: $21^{\circ}$ Congresso Brasileiro de Engenharia e Ciência dos Materiais; 2014 Nov 9-13; Cuiabá, Mato Grosso, Brazil. Proceedings. São Paulo: ABM. p. 2741-2748.
57. Shah AA, Hasan F, Hameed A, Ahmed S. Biological degradation of plastics: A comprehensive review. Biotechnol Adv. 2008;26(3):246-65.

58. Touati N, Kaci M, Bruzaud S, Grohens Y. The effects of reprocessing cycles on the structure and properties of isotactic polypropylene/cloisite 15A nanocomposites. Polym Degrad Stabil. 2011;96(6):1064-73.

59. Thompson MR, Yeung KK. Recyclability of a layered silicatethermoplastic olefin elastomer nanocomposite. Polym Degrad Stabil. 2006;91(10):2396-407. 